\title{
CLINICAL RESEARCH
}

\section{Outcome of pregnancy in leatherworkers}

\author{
A D McDONALD, J C MCDONALD
}

\begin{abstract}
A recent proposal that leatherworkers might face a reproductive hazard was tested using data from a large survey in Montreal of occupational factors in pregnancy. The outcome of pregnancy in almost 400 women employed in the manufacture of leather products, some 6000 employed in other types of manufacture, and nearly 50000 employed but not in manufacture were compared. There was little difference between the groups in the rates of congenital malformation and spontaneous abortion, but the leatherworkers had a significant excess of stillbirths without defect (eight observed compared with fewer than three expected).
\end{abstract}

The possibility of a fetotoxic agent-perhaps a constituent of glues or cements - should be investigated in the leather industry.

\section{Introduction}

In a recent report evidence was presented of a possible reproductive hazard in leatherwork.' Of 75000 deliveries to women resident in Leicestershire during 1976-82, 1187 resulted in stillbirth or infant death in the first week of life. Odds ratio estimates of the risk of perinatal death were raised in four of 27 occupational orders, one of which, leatherwork, was considered to be of particular interest. This conclusion was based on the specificity of the working material and environment and the fact that an excess of this magnitude was unlikely to have occurred by chance. The odds ratio for the leatherworkers when compared with other manual workers in social class III in the county was $2 \cdot 1$, an increase not explained by age, parity, legitimacy, ethnicity, or height. The 36 perinatal deaths among the offspring of leatherworkers included an excess associated

\footnotetext{
Institut de Recherche en Santé et en Sécurité du Travail, Montréal, Québec, Canada

A D MCDONALD, MD, FFCM, research director

School of Occupational Health, McGill University, Montréal, Québec, Canada

J C MCDONALD, MD, FRCP, professor

Correspondence to: Dr A D McDonald.
}

with congenital malformations (odds ratio $3 \cdot 1$ ) and fetal maceration (odds ratio $2 \cdot 6$ ). Of 12 deaths with malformation, three were attributed to trisomy 18 , a rare chromosomal anomaly with a stated frequency of one in 5000-7000 births. The other defects were not described.

A large survey of work and pregnancy in Montreal, begun in 1982 , is now being analysed. Data from this survey seemed suitable for us to test independently the hypothesis that leatherwork is associated with risk to the fetus.

\section{Methods \\ THE MONTREAL SURVEY}

Altogether 56012 women were interviewed from 11 May 1982 to 10 May 1984 immediately after delivery $(51885)$ or spontaneous abortion (4127) in 11 hospitals covering some $90 \%$ of births in Montreal. Questions were asked systematically in English or French on employment and personal factors by bilingual nurse interviewers using an eight page questionnaire. Information was thus obtained for the 56012 current and 48608 past pregnancies of these women (104620 pregnancies in all). Employment was coded according to the Standard Occupational Classification of Statistics Canada (1980) (four digits were used) and the Standard Industrial Classification of Statistics Canada (1980) (two digits were used) by a clerk experienced in coding occupations for the 1981 Canadian Census. This information was supplemented by detailed questions on various types of occupational exposure and ergonomic aspects of work undertaken by the women during their pregnancies. Hygienists later made further inquiries by visits or telephone calls to the workplace in selected cases and controls.

In the ascertainment of outcome of pregnancy special attention was paid to spontaneous abortion, birth weight, gestational period, and congenital defect. This information was obtained from medical records of current pregnancies and by questions to the mothers on previous pregnancies. In both cases these data were supplemented by further inquiries addressed to physicians and hospitals.

\section{PRESENT ANALYSIS}

The data used by Clarke and Mason ${ }^{1}$ and those from the Montreal survey differ somewhat. Their data were limited to perinatal deaths with and without malformation; our data included all major malformations whether or not fatal, plus stillbirths and neonatal deaths without recorded malformation. In our study of major malformations in live and stillborn intants and of stillbirths without malformation we focused on 6306 pregnancies ( 3120 
previous and 3186 current) of women who were employed during the first trimester for at least two weeks in selected manufacturing occupations. The selection was made first by taking division $\mathrm{E}$ (manufacturing industries) and then limiting the sample to four major groups-namely, $81 / 82$ (processing), 83 (machining), 85 (fabricating, assembling, and repairing), and 93 (material handling). Of the 6306 pregnancies in this group, $3779(60 \%)$ were in women who were concerned with clothing and textiles; $913(15 \%)$ in women working with metal, electrical, and chemical products; $337(5 \%)$ in women working with food and beverages; $346(5 \%)$ in women working with leather and allied products; and $931(15 \%)$ in women working with miscellaneous products.

We additionally examined rates of spontaneous abortion in 7239 women in relation to their employment at the start of pregnancy. In this analysis allowance was made by logistic regression for the confounding effects of maternal age, parity, history of abortion, education, and smoking. In effect we calculated an expected number of spontaneous abortions, allowing for these variables, for comparison with the observed numbers. A comprehensive report on rates of spontaneous abortion by occupation and related factors and the statistical methods used will be published elsewhere. In the present paper work state was defined differently in the two analyses. In the study of stillbirths and malformations women were classified according to their employment for at least two weeks during the first trimester; for abortions women were classified according to their employment at the start of pregnancy. This was necessary because women who abort early do so within the first trimester. To this extent the denominators are not exactly comparable.

A much higher rate of abortion was found in previous than current pregnancies. This was because, firstly, any recent conception-certainly if within one year of a current delivery-must of necessity have ended in abortion, and, secondly, only about half the women who aborted were admitted to hospital and then seldom for long. We estimate that our interviewers managed to reach only about $75 \%$ of those admitted for this reason before their discharge. Women who had a stillbirth were kept in hospital for a much shorter time than those who had a liveborn child, and some could not be interviewed because they were too distressed. We estimate that in consequence stillbirths in current pregnancies were underrepresented by about $50 \%$. On the other hand, we believe that stillbirths in previous pregnancies were fully reported.

\section{Results}

After 818 multiple pregnancies, 15037 spontaneous abortions, and 272 pregnancies for which the data were incomplete had been excluded 88493 deliveries of a single live or stillborn child remained. Table I shows the outcome of these pregnancies in relation to whether or not any paid work was undertaken by the woman for two weeks or more during the first trimester. The rates appear to follow a systematic pattern: major congenital defects were slightly more common in pregnancies of women employed in manufacture than in those of women employed in other work or not employed. The experience of the leatherworkers was similar to that of women in other types of manufacture: six defects were observed wherease 5.2 would have been expected from the rate in non-manufacturing work. $C$ The rate for stillbirths without defect, on the other hand, was some $50 \%$ higher in women employed in manufacture compared with other types of work. The leatherworkers fared much worse than other women: eight cases] were observed compared with 2.8 expected from the rate in other manufacturing jobs $\left(\chi_{c}^{2}=6 \cdot 13, p<0.02\right)$ or 2.0 expected from the rate form women employed but not in manufacturing $\left(\chi_{c}^{2}=14.49, p<0.005\right)$. In fact, the excess was all in previous pregnancies, with seven cases observed against 1.92 expected $\left(\chi_{c}^{2}=8.92, p<0.005\right)$. In current pregnancies one case was observed and 0.95 expected. The difference in the ratio of observed too expected cases in current $(1.05)$ and previous pregnancies $(3.65)$ was noo more than could be explained by chance $(p>0 \cdot 10)$.

As the numbers of women employed in the manufacture of leather products who went to term was small (346) it is difficult to interpret the absence of an excess of congenital defects with confidence. The majorês congenital abnormalities observed in this series (with approximate numbers expected from the entire survey) were: omphalocele two $(0 \cdot 145)$, phocomelia one $(0.002)$, polycystic kidney one $(0.073)$, hypospadias one $(0.865), \vec{\omega}$ microcephaly one $(0 \cdot 142)$, and other defects none $(4 \cdot 256)$. Thus althougho two cases of omphalocele and even one of phocomelia give cause for thought, the deficiency in other types of defect puts this in perspective. Twenty two. cases of trisomy 18 were identified in the Montreal survey, giving an observed frequency of one case per 4022 births, but none was in children of leatherworkers.

The evidence of excess fetal mortality after the 28th week of gestation (thaf is, of stillbirths) in leatherworkers led us also to examine our data or spontaneous abortion. Table II shows that the ratios of observed to expected numbers of abortions after correction for confounders were higher iro working than non-working women and somewhat higher in leatherworkers than in women employed in other manufacturing work. The difference wa $\vec{\sim}$ slightly greater in current pregnancies $(1.19 v 1.01)$ than in past pregnancies $(1.04 v 0.94)$, but even taken together the combined difference was of low significance $\left(\chi^{2}=0.73, p=0.19\right)$. The data were also examined in three periods of gestation (one to eight weeks, nine to 16 weeks, and 17-27 weeks) but there was no evidence that the relatively small differences observed were concentrated in any way.

\section{Discussion}

In our analysis of stillbirths and malformations (table I) we diक not adjust for the possible effect of confounding variables. Thes analysis of abortion (table II), however, shows that women who

TABLE I-Numbers of stillbirths without defect and major congenital defects in single live or stillborn infants related to type of paid work undertaken by mother during pregnancy

\begin{tabular}{lccc}
\hline \multicolumn{1}{c}{ Occupational category } & $\begin{array}{c}\text { No of pregnancies } \\
(\geqslant 28 \text { weeks) }\end{array}$ & $\begin{array}{c}\text { No(\%) of stillbirths } \\
\text { without defect }\end{array}$ & $\begin{array}{c}\text { No(\%) of major } \\
\text { congenital defects }\end{array}$ \\
\hline Not employed & 37482 & $223(0 \cdot 59)$ & $621(1 \cdot 66)$ \\
Employed, but not in manufacture & 45705 & $261(0 \cdot 57)$ & $673(1 \cdot 47)$ \\
Employed in manufacture & 6306 & $57(0 \cdot 90)$ & $110(1 \cdot 74)$ \\
Of leather products & 346 & $8(2 \cdot 31)$ & $6(1 \cdot 73)$ \\
Of other products & 5960 & $49(0 \cdot 82)$ & $104(1 \cdot 74)$ \\
\hline
\end{tabular}

^Based on paid employment for two weeks or more during first 13 weeks of pregnancy.

TABLE II Spontaneous abortion rates and ratios of observed to expected ${ }^{\star}$ numbers of abortions related to maternal occupation at start of pregnancy

\begin{tabular}{|c|c|c|c|c|c|c|c|c|}
\hline \multirow[b]{2}{*}{$\begin{array}{l}\text { Occupational category at start } \\
\text { of pregnancy }\end{array}$} & \multicolumn{4}{|c|}{ Current pregnancies } & \multicolumn{4}{|c|}{ Previous pregnancies } \\
\hline & $\begin{array}{c}\text { No of } \\
\text { pregnanciest }\end{array}$ & $\begin{array}{c}\text { No }(\%) \text { of } \\
\text { spontaneous } \\
\text { abortions }\end{array}$ & $\begin{array}{c}\text { No } \\
\text { expected }\end{array}$ & $\begin{array}{l}\text { Observed: } \\
\text { expected }\end{array}$ & $\begin{array}{c}\text { No of } \\
\text { pregnancies }\end{array}$ & $\begin{array}{c}\text { No }(\%) \text { of } \\
\text { spontaneous } \\
\text { abortions }\end{array}$ & $\begin{array}{c}\text { No } \\
\text { expected }\end{array}$ & $\begin{array}{l}\text { Observed: } \\
\text { expected }\end{array}$ \\
\hline Not employed & 25040 & $1859(7 \cdot 4)$ & $2031 \cdot 69$ & 0.92 & 22304 & $5045(22 \cdot 6)$ & $6369 \cdot 95$ & 0.79 \\
\hline Employed, but not in manufacture & 27598 & $2014(7 \cdot 3)$ & $2007 \cdot 21$ & 1.00 & 22425 & $5003(22 \cdot 3)$ & 5090.56 & 0.98 \\
\hline Employed in manufacture & 3366 & $252(7 \cdot 5)$ & $246 \cdot 52$ & 1.02 & 3873 & $859(22 \cdot 2)$ & 905.92 & 0.95 \\
\hline Of leather products & 171 & $14(8 \cdot 2)$ & $11 \cdot 72$ & $1 \cdot 19$ & 224 & $57(25 \cdot 4)$ & $55 \cdot 07$ & 1.04 \\
\hline Of other products & 3195 & $238(7 \cdot 4)$ & $234 \cdot 80$ & 1.01 & 3649 & $802(22 \cdot 0)$ & $850 \cdot 85$ & 0.94 \\
\hline
\end{tabular}

*Obtained by logistic regression analysis in current and previous pregnancies.

†Eight current and six previous pregnancies were excluded because of lack of information on occupation. 
were employed in manufacturing and non-manufacturing work had almost identical rates of abortion, and this relativity was not affected after logistic regression had accounted for differences in age, parity, history of abortion, education, and smoking. Thus there were no important differences between the two groups in these respects.

This study thus provides support for the findings of Clarke and Mason that leatherwork in pregnancy may be associated with an increased risk of stillbirth. ' The excess was entirely in the previous pregnancies, for which our data were complete and, we believe, reliable. In current pregnancies, in which stillbirths were incompletely ascertained, the absence of excess (one observed against 0.95 expected) is based on numbers too small to be interpreted. The difference between the ratio of observed to expected cases in current and previous pregnancies is no more than can be explained by chance. We did not, however, find any convincing evidence of an increase in fetal malformations. The only type of congenital defect on which Clarke and Mason commented were the three cases of trisomy 18 in an estimated 1200 births, or one in 400 . As we had only 346 term pregnancies in leatherworkers and no case of trisomy 18 we are not able to confirm or refute their finding.
There is not necessarily any contradiction in finding a hazard that causes stillbirth and not malformation. A toxic agent acting later in pregnancy even over a short period could kill a fetus, whereas our knowledge of teratology suggests that only an agent acting at the right time in the first trimester might cause a malformation.

The findings of Clarke and Mason and our own suggest that leatherwork may possibly expose women to a fetotoxic agent. We examined the work histories of the eight women in our study whose infants were stillborn; all operated sewing machines, three manufacturing shoes, three bags, and one belts. Five of the eight described exposure to glues (or cements, or both), one to paint, and one to silicone. It seems desirable to investigate the possible fetotoxicity of materials used in the manufacture of leather products.

\section{Reference}

1 Clarke M, Mason ES. Leatherwork: a possible hazard to reproduction. Br Med J 1985;290:1235-7.

(Accepled 14 Februany 1986)

\title{
Remission of symptoms during long term treatment of metastatic pancreatic endocrine tumours with long acting somatostatin analogue
}

\author{
J L C CH'NG，J V ANDERSON，S J WILLIAMS， D H CARR，S R BLOOM
}

\begin{abstract}
Five patients with metastatic pancreatic endocrine tumours injected a long acting somatostatin analogue (SMS 201-995) $50 \mu \mathrm{g}$ subcutaneously every 12 hours and were followed up for three to six months. Treatment aimed at controlling excess secretion of hormone by the tumours thereby bringing symptomatic relief.
\end{abstract}

Four patients showed a significant reduction in tumour related hormone concentrations but in none did values return to normal. All five patients, however, noted definite symptomatic improvement and in one this was dramatic (disappearance of life threatening diarrhoea and correction of metabolic acidosis and hypokalaemia within 48 hours). Mild worsening of symptoms and increasing fasting tumour related hormone concentrations after three to six months of treatment were reversed by doubling the 12 hourly dose. The treatment was well tolerated and had no deleterious effect on fasting blood glucose concentrations.

This somatostatin analogue seems a promising non-invasive treatment for metastatic pancreatic endocrine tumours.

\footnotetext{
Department of Medicine, Royal Postgraduate Medical School, Hammersmith Hospital, London W12 0HS

J L C CH'NG, MB, MRCP, research fellow and honorary registrar

J V ANDERSON, MA, MRCP, research fellow and honorary registrar

$\mathrm{S} J$ WILLIAMS, BSC, research assistant

$S$ R BLOOM, MD, FRCP, professor of endocrinology

Department of Radiology, Royal Postgraduate Medical School, Hammersmith Hospital, London W12 0HS

D H CARR, MD, FRCR, senior lecturer in diagnostic radiology

Correspondence to: Professor Bloom.
}

\section{Introduction}

Pancreatic endocrine tumours (apudomas), being slow growing malignancies, cause morbidity and mortality by virtue of the excess hormones that they secrete. Most patients have metastases at presentation, and treatment is then palliative. In contrast with many other metastatic malignancies, however, years of symptomatic relief may result if the tumour related hormone excess can be controlled. Current methods of treatment are surgical debulking, arterial embolisation of hepatic metastases, and chemotherapy. Native 14 amino acid somatostatin has been shown to have potent antisecretory properties on these tumours. ${ }^{1}$ To be therapeutically useful a long acting and conveniently administered analogue is needed. We report the preliminary results of using such an analogue (SMS 201-995, Sandoz Laboratories, Basle).

\section{Patients and methods}

We studied five patients with metastatic pancreatic endocrine tumours. Two patients had tumours secreting vasoactive intestinal polypeptide (vipomas), two had glucagonomas, and one had a tumour producing growth hormone releasing factor. Four of the patients had relapsed after other forms of treatment, while one declined chemotherapy and invasive forms of treatment.

Before starting treatment with SMS 201-995 we assessed the patient's clinical condition, tumour related hormone concentration, blood glucose concentration, and tumour bulk (by computed tomography; CT). The acute tumour related hormone response to a test dose of 50 $\mu \mathrm{g}$ SMS 201-995 subcutaneously was also determined.

Initial treatment was with $50 \mu \mathrm{g}$ SMS 201-995 given subcutaneously every 12 hours. The patients injected the analogue, using a method similar to insulin injections in diabetics. Full clinical and hormonal evaluation was undertaken every three months. Two patients were followed up for six months and three patients for three months.

Tumour related hormone concentrations were measured by radioimmunoassay. ' 